\title{
Liquid Phase Oxidation of Xylenes: Effects of Water Concentration and Alkali Metals
}

\author{
Sung Hwa Jhung," Ki Hwa Lee, and Youn-Seok Park \\ Samsthg General Chemicals Co., Lid. \\ San 222-2, Dokgod-Ri, Daesan-Lip, Seosan-Si, Chungnam 356-711, Korea \\ Recerved August $1 \mathrm{H}_{1} 2001$
}

\begin{abstract}
A facile and precise batch oxidation reaction sy stem allows continuous monitoring of the oxidation rate and cumulated oxygen conversion of xylenes. and the side reactions to carbon monoxide and carbon dioxide may also be studied. The oxidation reaction can be analyzed precisely with the rate and amount of oxygen consumed. The reaction reveals that 4-carboxybenzaldehyde is an unstable intermediate of p-xylene oxidation as the reaction proceeds instantaneously from p-toluic acid to TPA (terephthalic acid). The alkali metals accelerate oxidation, even though they retard the reaction initially. The oxidation rate increases with decreasing water concentration. However. in the later part of reaction the reactivity decreases a bit if the water concentration is very low. This retarding effect of water can be overcome partly by the addition of potassium. The oxidation of o-xylene. compared with the oxidation of p-xylene and m-xylene. proceeds quite fast initially. however. the oxidation rate of xylene isomers in the later stage of reaction is in the order of p-xylene $>\mathrm{m}$ xylene $>0-x y l e n e$.
\end{abstract}

Keywords : Terephthalic acid. p-Xylene oxidation, Water concentration, Alkali metal

\section{Introduction}

Terephthalic acid (TPA) is one of the most inportant chemicals. with an annual production capacity of more than 24.000 .000 tons in the year 2000 . Korea has the highest TPA capacity, $4.540,000$ tons/year. TPA, the raw material of polyester. is usually produced commercially by liquid phase oxidation of $\mathrm{p}$-xylene ( $\mathrm{pX}$ ) with air. using a catalyst combination of cobalt. manganese and bromide ions in acetic acid at around $170-210^{\circ} \mathrm{C}$

Detailed studies on the kinetics ${ }^{+10}$ and mechanism ${ }^{4.5 .11-17}$ of the liquid phase oxidation of alkylaromatics to aromatic carboxylic acids have been conducted. It has also been attempted to replace the acetic acid solvent with water ${ }^{18.15}$ and to eliminate the corrosive bromine component $\mathrm{t}^{-1.21}$ and to utilize carbon dioxide as a co-oxidant. ${ }^{2}$ There have also been numerous efforts ${ }^{4.5 .23 .24}$ to improve the $\mathrm{Co} / \mathrm{Mn} / \mathrm{Br}$ catalyst system including the incorporation of transition and lanthanide metals such as $\mathrm{Zr}$. Ce, $\mathrm{Hf}$ and Mo

Considering the huge production of TPA. even snall improvements in the process are very important from an econonic viewpoint. The desirable improvements in the TPA production process include ${ }^{3}$ : i) decrease the destruction of raw materials and solvent; ii) increase the selectivity of the reaction to eliminate the purification step. hydrogenation. in water solvent; iii) replace the corrosive acetic acid with water and $\mathrm{HBr}$ with a non-corrosive free-radical carrier.

A better understanding of the mechanism and effects of the process parameters are essential to improve a process. However, in this case, expectations are not high because the

${ }^{*}$ Conesponding author. Tel: +82-41-660-6162: Fax: +82-41-6606169; e-mail: shihung atsansung co.kr
TPA process has been optimized for last several decades. ${ }^{25}$

However. because of the extremely low solubility of TPA (for example. the degree of precipitation of TPA in acetic acid at $100{ }^{\circ} \mathrm{C}$ is $99.4 \%{ }^{4}$ ), checking the oxidation of $\mathrm{p}$ sylene precisely, especially in a reaction condition similar to that of usual conmercial operations, is very difficult. Instead. the reaction is carried out usually at low temperature far from the actual commercial condition. and the conversion to TPA is very low. The material balances of aromatics and acetic acid are quite low because of the difficulty in separating and recovering products and evaporation of raw materials in the case of continuous feeding of reactant or oxidation gas.

Because of the diminishing retums of research on the TPA process. ${ }^{25}$ precise and reproducible measurements of $\mathrm{p}$ sylene oxidation are essential to improve the process.

Research shows that water retards the oxidation of alkylaromatics. such as p-xylene. ${ }^{412}$ However. the effects of water in various conditions are not well known. The effects of alkali metal on the oxidation of p-xylene have not been studied in detail because of the constant valence of alkali netals.

In this paper. a facile and precise batch oxidation system to monitor the oxidation of p-sylene in nearly actual commercial operation conditions is reported. Also. the effects of alkali metals and water concentration on the oxidation of $p$ sylene are discussed. The relative activity of xylene isomers, such as p-xylene, m-xylene ( $\mathrm{mX}$ ) and o-xylene $(\mathrm{oX})$. is reported briefly

\section{Experimental Section}

Apparatus. The oxidation reaction was carried out in a 


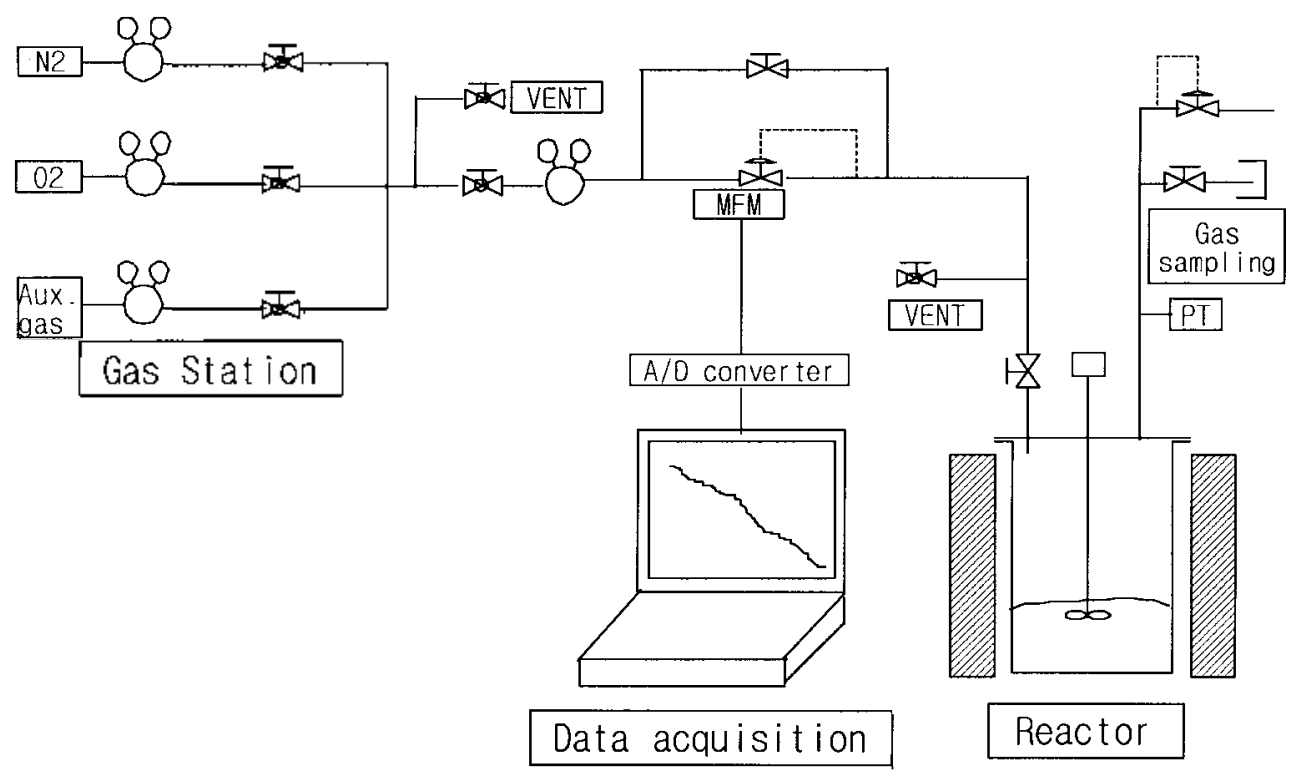

Figure 1. Schematic diagram of the batch oxidation system.

batch mode. except for oxygen, using the apparatus in Figure 1. The reactor a titanium autoclave with a capacity of $450 \mathrm{~mL}$, was composed of an agitator. gas inlet and outlet ports, and an electric furnace. The oxygen was supplied through the inlet port simultaneously as it was consumed via the oxidation of xylene isomers. The amount of consumed oxygen for oxidation was monitored continuously with the digitized signal of a MFM (mass flow meter). In this way. the reaction speed and cumulated conversion were monitored continuously. The gas phase composition was analyzed after venting through the outlet port either during the course of the reaction or after the reaction.

Procedure. $200 \mathrm{~g}$ of reactant (15\% xylene isomer, $7.5 \%$ water and $77.5 \%$ acetic acid) were charged in the titanium reactor. The expected oxygen consumption was $848 \mathrm{mmol}$ based on the stoichiometry of xylene isomer oxidation only. To ascertain the effects of water concentration, the concentration of water was changed from 7.5 to $2.5-12.5 \%$. and the concentration of acetic acid was changed accordingly from $77.5 \%$ to $82.5-72.5 \%$. Based on the total weight of the reaction mixture, the catalyst comprised 100 ppm of cobalt. $200 \mathrm{ppm}$ of manganese (for some cases 100 ppm) and $300 \mathrm{ppm}$ of bromine. If necessary, alkali metal ions, such as $\mathrm{Li}^{+} . \mathrm{Na}^{+}, \mathrm{K}^{-}$and $\mathrm{Cs}^{-}$, with the atomic concentration that corresponds to that of $\mathrm{Br}$. were added. In other words, $26 \mathrm{ppm}$ of $\mathrm{Li}^{-}, 86 \mathrm{ppm}$ of $\mathrm{Na}^{-}, 147 \mathrm{ppm}$ (for some case. $98 \mathrm{ppm}$ ) of $\mathrm{K}^{+}$or $499 \mathrm{ppm}$ of $\mathrm{Cs}^{+}$was added.

While stirring, the reactor was heated to the temperature $185^{\circ} \mathrm{C}$ in a nitrogen atmosphere. To check the effects of the reaction temperature. the reaction was performed at 180-195 ${ }^{\circ} \mathrm{C}$. As soon as the reaction temperature was reached. nitrogen was added up to the pressure of 14 atmospheres. followed by the addition of oxygen instantly up to 28 atmospheres. Oxygen consumed by the oxidation of xylene isomer was spontaneously compensated for with fresh oxygen through a mass flow meter. The consumption rate of oxygen was monitored continuously by the flow rate of oxygen. After the predetemined reaction time or oxygen consumption was reached, the reaction was quenched by the discontinuation of oxygen flow and cooling the reactor.

Reagent. Cobalt acetate tetrahydrate, manganese acetate tetrahydrate and hydrogen bromide were used to prepare the catalyst solution. Lithium nitrate. sodium acetate trilydrate. potassium acetate. and cesium acetate were employed as sources of alkali metal. All other chemicals. including xylene isomers and acetic acid, were guaranteed reagent grades.

Analysis. The gas phase composition, such as nitrogen, oxygen. carbon dioxide and carbon monoxide, was analyzed using GC with a TCD detector after sampling with an outlet port either in the course of a reaction or after a reaction.

After the reactor was cooled to room temperature. the resulting product was subjected to solid-liquid separation. such as filtration. The recovered solid product was washed. dried and analyzed with HPLC to determine the content of TPA. p-toluic acid (p-tol) and 4-carboxybenzaldehyde (4CBA). The column was C-18 (RP) and the detector was UVDAD (254. $290 \mathrm{~mm})$, and the eluent was $1 \%$ acetic acid/ acetonitrile $(20 / 80 \%$ to $40 / 60 \%)$. Before analysis with HPLC, $0.5 \mathrm{~g}$ of solid was dissolved in $100 \mathrm{~mL}$ of $1 \%$ $\mathrm{NH}_{4} \mathrm{OH}$. The liquid component separated from the solid product also was analyzed by HPLC after a 100 -fold dilution with acetic acid.

The liquid component also was analyzed with GC to check the content of water, acetic acid and sylene isomers. The detector was TCD type and the column was a Tenax TAA $60 / 80$. The oven temperature was programmed from 100 to $230^{\circ} \mathrm{C}$.

The conversion of $\mathrm{p}$-sylene. product distribution. TPA yield and aromatic balance was calculated with the analysis results. 


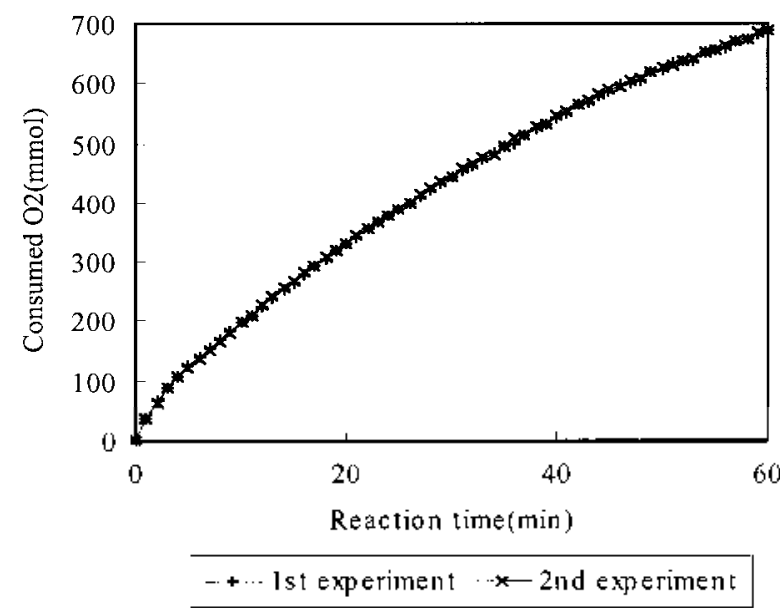

Figure 2. The reproducibility of experiments to measure the oxygen consunption.

\section{Results and Discussion}

Probing the oxidation and effects of alkali metals. The oxygen consumption may represent precisely the oxidation of a substrate if the amount of side reactions of raw materials and solvent yielding carbon monoxide and carbon dioxide $(\mathrm{COx})$. etc. are relatively low. The selectivity of p-xylene oxidation is very high for the catalyst system of $\mathrm{Co} / \mathrm{Mn} /$ Br. ${ }^{4,14}$ Therefore. if we can monitor the oxygen consumption precisely we can gain much information on the oxidation of p-xylene, even though the products are not analyzed due to the very low solubility ${ }^{+}$of the samples and the difficulty of recovery.

First of all, the reproducibility of oxygen consumption with the apparatus is extremely high, with a relative error of within $1 \%$ for the case when oxygen conversion is higher than $25 \%$ (Figure 2). Therefore. a very small change in activity or reaction pattern can be checked with the batch reactor.

Figure 3 shows the difference in the consumption rate of oxygen, compared with the catalyst $\mathrm{Co} / \mathrm{Mn} / \mathrm{Br}$. with the addition of alkali metals with reaction time. When the concentration of alkali metal is equal to that of $\mathrm{Br}$ in atonic concentration. $26 \mathrm{ppm}$ of $\mathrm{Li}^{-}, 86 \mathrm{ppm}$ of $\mathrm{Na}^{-}, 147 \mathrm{ppm}$ of $\mathrm{K}^{+}$ or $499 \mathrm{ppm}^{-} \mathrm{Cs}^{-}$, the oxidation rate is low compared with that of $\mathrm{Co} / \mathrm{Mn} / \mathrm{Br}$ for a reaction time of around $10 \mathrm{~min}$.

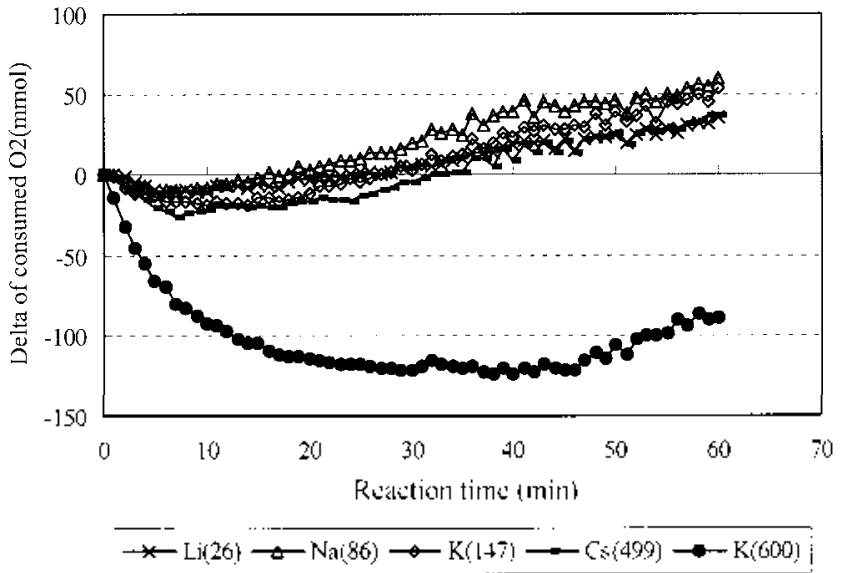

Figure 3. The difference of consumed oxygen with time with the addition of alkali metals.

However. the rate is high after a reaction of about $30 \mathrm{~min}$ When the concentration of added alkali metal is very high. for example $600 \mathrm{ppm}$ of $\mathrm{K}$. the reaction rate is very low. The oxidation of $\mathrm{p}$-sylene can eventually be accelerated by the addition of an alkali metal in a suitable concentration. The detailed effects of alkali metal on the oxidation of xylene isomers are discussed elsewhere. th $^{\text {th }}$

Table 1 shows the product distribution. TPA yield and balance of aromatic compounds with the added alkali metal or consumed oxygen after a reaction time of $60 \mathrm{~min}$. The yield of TPA is high when an alkali metal with the concentration of $\mathrm{Br}$ is added. The dependence of p-toluic acid, 4carboxybenzaldelyde, and TPA concentration and TPA yield on the consumed oxygen is shown in Figure 4. The consumed oxygen reflects the oxidation of p-xylene quite well. Also. we found that 4-carboxybenzaldehyde is an unstable intermediate. and the reaction proceeds instantaneously from p-toluic acid to TPA as described by Sheldon and $\mathrm{Kochil}^{27}$ and Partenheimer. ${ }^{+}$

With the batch reactor without any evaporation of raw materials the aromatic balances are as high as $95 \%$ as shown in Table 1. With the semi-batch reaction, continuous feeding of air or oxygen. obtaining an aromatic balance of more than $90 \%$ was impossible ${ }^{\text {? }}$

The amount of produced carbon monoxide and carbon dioxide is very important because the COx formed due to the

Table 1. Effects of alkali metals on the amount of consumed oxygen, product distribution and TPA yield by the reaction of $60 \mathrm{~min}$

\begin{tabular}{|c|c|c|c|c|c|c|c|c|c|}
\hline \multicolumn{2}{|c|}{ Catalyst } & \multirow{2}{*}{$\begin{array}{l}\text { Consumed } \mathrm{O}_{2} \\
(\mathrm{mmol})\end{array}$} & \multicolumn{3}{|c|}{ Product distribution ( $\mathrm{mol} \%$ ) } & \multirow{2}{*}{$\begin{array}{l}\text { TPA yield } \\
(\%)\end{array}$} & \multirow{2}{*}{$\begin{array}{c}\text { Aromatic } \\
\text { balance } \\
(\%)\end{array}$} & \multicolumn{2}{|c|}{ Gas composition (vol. \%) } \\
\hline $\begin{array}{l}\text { Added } \\
\text { catalyst }\end{array}$ & $\begin{array}{l}\text { Concentration } \\
\text { (ppmin) }\end{array}$ & & $\mathrm{p}$-toluic acid & 4-CBA & TPA & & & $\mathrm{CO}$ & $\mathrm{CO}_{2}$ \\
\hline None & - & 687.2 & 40.2 & 10.3 & 49.5 & 45.6 & 95.4 & 5.6 & 17.0 \\
\hline $\mathrm{Li}$ & 26 & 723.0 & 30.9 & 10.1 & 59.1 & 56.5 & 97.6 & 6.2 & 18.5 \\
\hline $\mathrm{Na}$ & 86 & 747.1 & 27.2 & 9.8 & 63.1 & 58.5 & - & 6.2 & 19.7 \\
\hline $\mathrm{K}$ & 147 & 741.4 & 26.1 & 9.5 & 64.5 & 59.2 & 95.0 & 5.5 & 16.8 \\
\hline $\mathrm{Cs}$ & 499 & 724.2 & 32.7 & 10.1 & 57.3 & 54.6 & 97.3 & 6.1 & 18.7 \\
\hline $\mathrm{K}$ & 600 & 598.0 & 52.2 & 11.3 & 36.5 & 33.5 & 95.1 & 5.6 & 17.1 \\
\hline
\end{tabular}




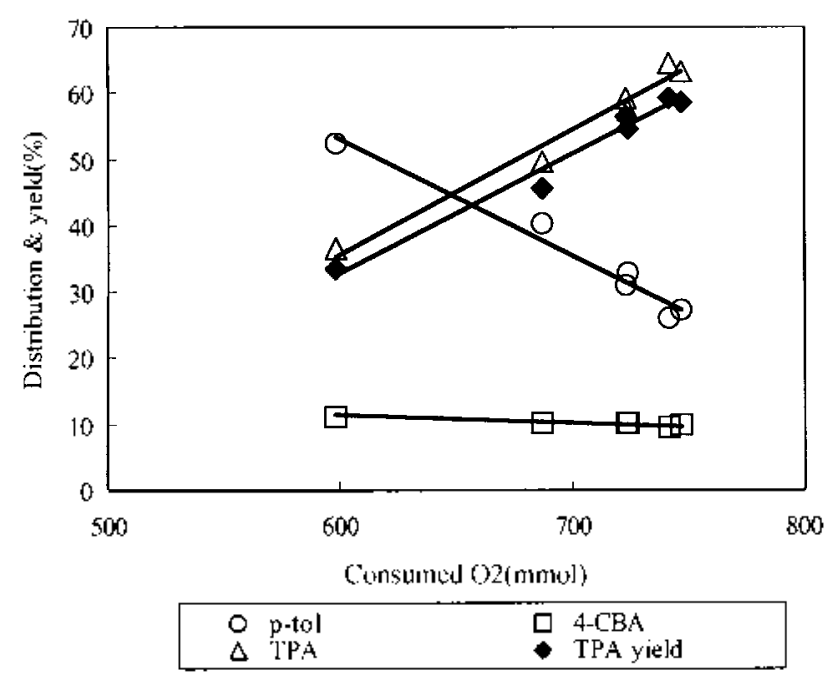

Figure 4 . Dependence of the product distribution and TPA vield with the consunned oxygent.

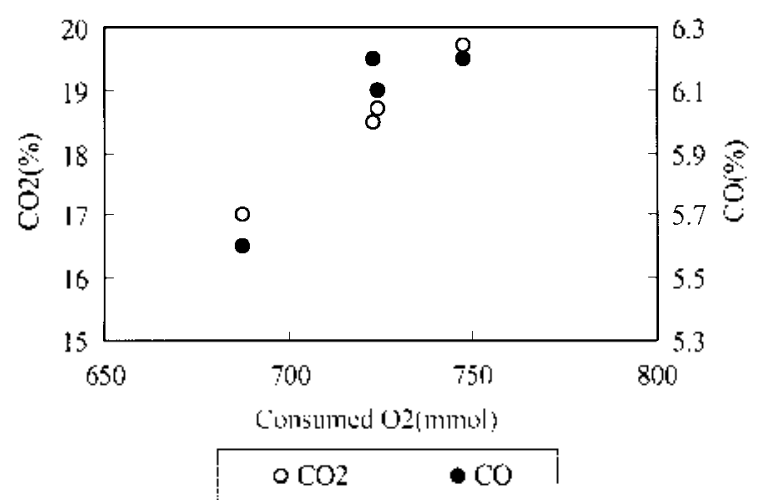

Figure 5. Dependence of the amount of carbon monoxide and carbon dioxide on the consuned oxygen during the oxidation of $\mathrm{p}$ sylene with the $\mathrm{Co} / \mathrm{Mr} / \mathrm{Br} / \mathrm{alk}$ ali metal (except for $\mathrm{K}$ ) catalyst sistem.

destruction of raw materials and solvent can represent the selectivity of a reaction. Figure 5 and Table 1 show that the amount of produced $\mathrm{COx}$ generally increases with the amount of consumed oxygen. except for the case of oxidation with $\mathrm{Co} / \mathrm{Mn} / \mathrm{Br} / \mathrm{K}$. In general. the destruction of raw materials to $\mathrm{COx}$ increases with the conversion of reaction. Apparently. the reaction system can be used to monitor the formation of $\mathrm{COx}$ or the selectivity of a reaction. The reason why the $\mathrm{COx}$ formed with the catalyst of $\mathrm{Co} / \mathrm{Mn} / \mathrm{Br} / \mathrm{K}$ is relatively low. compared with $\mathrm{Co} / \mathrm{Mn} / \mathrm{Br} /$ (other alkali metals) may be a result of a slightly higher selectivity of reaction caused by the added potassium because the consumed oxygen is a bit low with similar TPA yield. The decreased formation of $\mathrm{COx}$ with $\mathrm{Co} / \mathrm{Mn} / \mathrm{Br} / \mathrm{K}$, compared with $\mathrm{Co} / \mathrm{Mn} / \mathrm{Br} / \mathrm{Na}$, was observed in a continuous reaction. ${ }^{29}$ However. the possibility of an experimental error cannot be excluded. Noteworthy is the fact that the COx formation with the catalyst of $\mathrm{Co} / \mathrm{Mn} /$ $\mathrm{Br} / \mathrm{K}(600 \mathrm{ppm})$ is quite high. even though oxygen conversion is very low. In other words, the destruction of raw materials increases if the concentration of added potassium

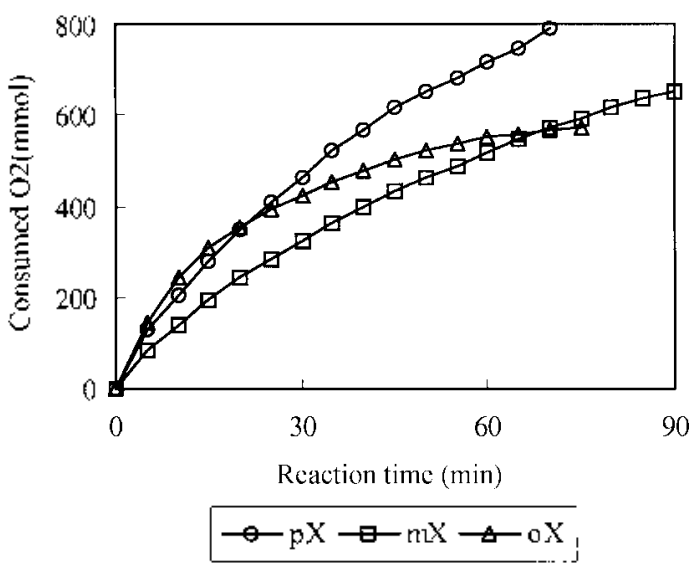

Figure 6. Oxidation rate of $\mathrm{p}$ - $\mathrm{m}$ - and $\mathrm{o}$-xylene.

(probably other alkali metals, also) is too high.

Figure 6 shows the oxidation rate of sylene isomers with the catalyst of $\mathrm{Co} / \mathrm{Mr} / \mathrm{Br}$ at $185^{\circ} \mathrm{C}$. The oxidation rate at the beginning of the reaction is o-xylene $>p-x y l e n e>m-x y l e n e$ as reported $d^{4}$. however. the rate of o-xylene sharply decreases with reaction time. probably due to i) deactivation by 0 toluic acid or o-phthalic acid; ii) the precipitation of metal catalysts as suggested. ${ }^{+}$It was reported that the two carbosylic acid groups in the ortho-position in the benzene ring deactivate oxidation more strongly than other positions due to decarbosylation of the aromatic acids. ${ }^{4}$ Finally. the reaction rate in the later part of the reaction is in the order of $\mathrm{p}$-xylene $>\mathrm{m}$-sylene $>0$-xylene due to the retardation of the oxidation of $o-x y l e n e$.

The oxidation rate (catalyst: $\mathrm{Co} 100 \mathrm{Mn} \mathrm{100}$. Br 300 ppm) with the temperature is shown in Figure 7. The rate at high temperature sharply decreases even though the rate in the beginning of the reaction increased with temperature. as can be anticipated easily. The reason why the rate sharply decreased at high temperatures in the later stage of the reaction should be clarified. One may imagine the formation of organic bromides or anti-oxidants, such as phenol, ${ }^{4}$ due to side reactions caused by high temperature.

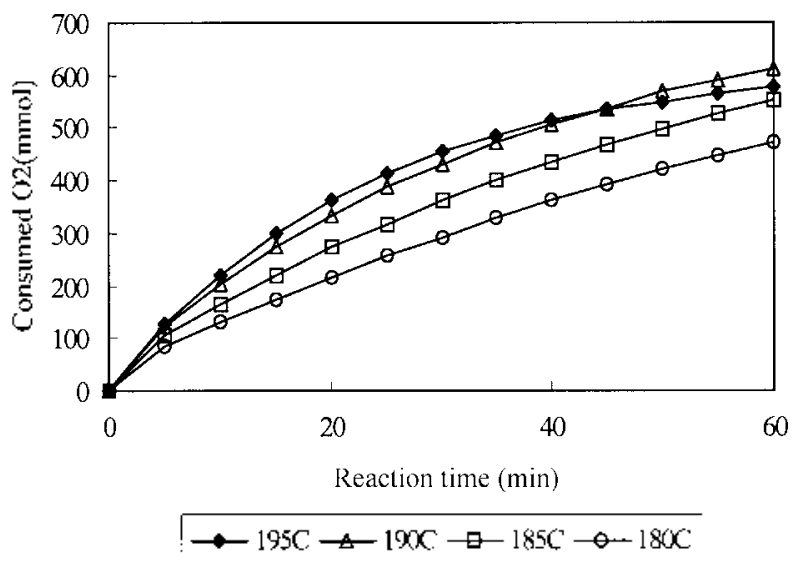

Figure 7. Effect of reaction temperature on the oxidation rate of pxylene with the catalyst of $100 \mathrm{ppm}$ of $\mathrm{Co}, 100 \mathrm{ppm}$ of $\mathrm{Mn}$ and 300 ppm of Br. 


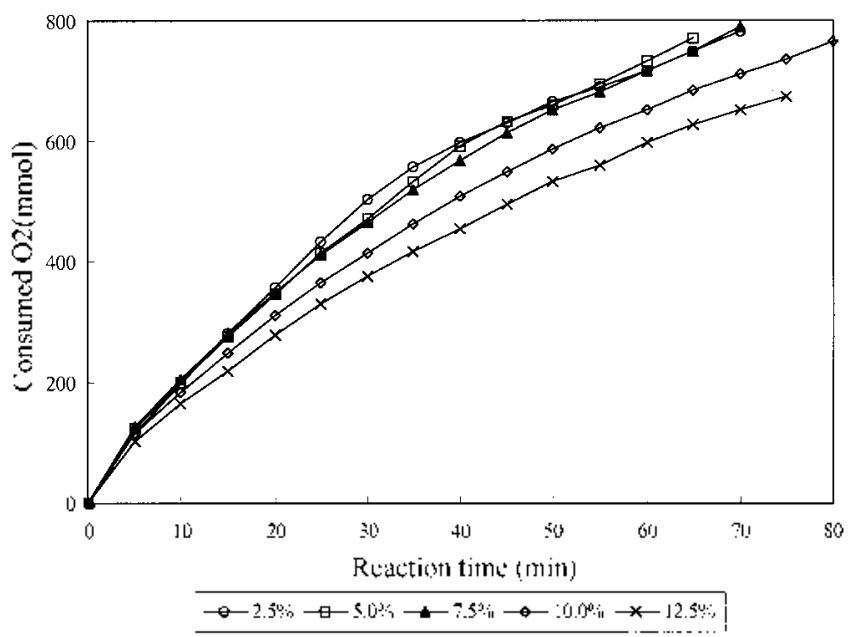

Figure 8. Effect of water concentration on the oxidation rate of pxylene with $\mathrm{Co} / \mathrm{Mn} / \mathrm{Br}$ catalyst.

The oxidation of p-xylene can be monitored very precisely with a batch reactor in conditions similar to those of a conumercial plant. The consumed oxygen represents the oxidation of p-xylene quite well. Alkali metals are understood to accelerate eventually the oxidation reaction. even though they retard the initial reaction.

However, we should point out that the anount of oxygen in the gas phase of the reactor should be high enough as not to control the reaction. In other words, if the oxygen concentration or volume of gas phase is too low. the reaction rate may be determined by the oxygen supply to the reaction mixture.

Effects of water concentration and potassium. Water retards the oxidation of alkylaromatics such as p-xylene. ${ }^{+.12}$ In Figures 8 and 10, the reaction rate of p-xylene increases as the concentration of water decreases up to $2.5 \%$. when the reaction time is about $25-40 \mathrm{~min}$ or oxygen conversion is about $50 \%$. However. as the reaction proceeds to completion. the rate of reaction. when the concentration of water is 2.5 or $5.0 \%$, decreases a bit. as compared with the case of a water concentration of $7.5 \%$ or more (see Figure 8 ). The

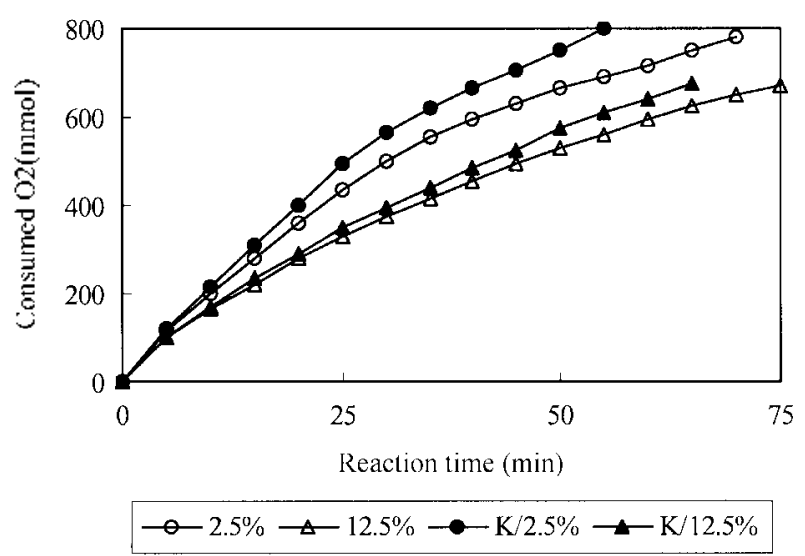

Figure 9. Effects of 98 ppin of $\mathrm{K}$ on the rate of p-xylene oxidation with water concentration of 2.5 and $12.5 \%$. reason why the rate decreases in low concentration of water in later part of reaction cannot be clarified at this moment. However. the precipitation of metal ions due to the low solubility in acetic acid. compared with the solubility in water might be one reason for the retardation. Moreover. the side reactions to organic bromides or anti-oxidants ${ }^{4}$ due to low selectivity of the reaction may be one of the reasons, as is the case for high reaction temperature

When we added $98 \mathrm{ppm}$ of potassium to the catalyst system the reduction of rate in the later stage of reaction was prevented, as can be seen in Figure 9. In other words, the added potassium also increased the oxidation rate in later stages of the reaction in all water concentration ranges investigated. The effects of water concentration on the oxidation rate when $98 \mathrm{ppm}$ of potassium were added is shown in Figure 10. The retardation of reaction when the water concentration was low (2.5 and $5.0 \%$ in Figure 8) could be prevented with the additional potassium, especially for the case of $5.0 \%$ of water (Figure 10). Without the additional potassium. the retardation commenced with a water concentration of $2.5 \%$ or $5.0 \%$ (see Figure 8 ). The effects of alkali metal on the oxidation of xylene isomers will be explained in detail elsewhere. ${ }^{26}$

Potassium can be used not only for increasing reaction rates but also for overcoming the retardation of reaction in its later stage when the water concentration is equal to about $5.0 \%$. If the water concentration is too low the rate of reaction, even with and without the additional potassium, decreases quite sharply, even though the rate is high in the earlier stage of the reaction

\section{Conclusions}

The oxidation of p-sylene can be monitored precisely and reproducibly with a batch reactor, and the oxidation reaction may be analyzed exactly by the rate and amount of oxygen consumption. Also. this study shows that 4-carbosybenzaldelyde is an unstable intermediate of p-xylene oxidation, and the reaction proceeds instantaneously from p-toluic acid

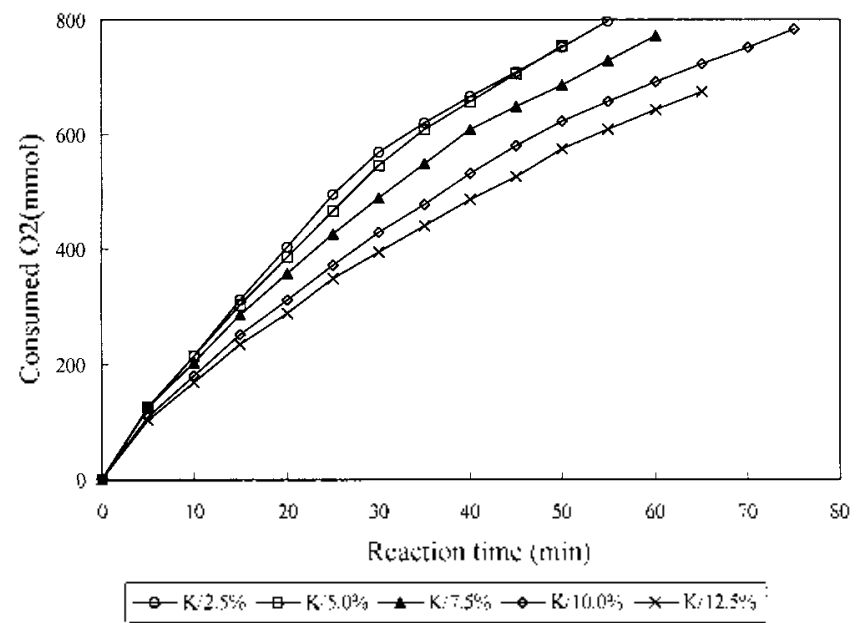

Figure 10. Effect of water concentration on the oxidation rate of $\mathrm{p}$ xylene with $\mathrm{Co} / \mathrm{Mn} / \mathrm{Br} / \mathrm{K}$ catalyst. 
to TPA. The alkali metals. including potassium, can eventually enhance the reactivity of $\mathrm{Co} / \mathrm{Mn} / \mathrm{Br}$ for the oxidation of p-xylene, even though an alkali metal retards the reaction in the earlier stage of the reaction. The oxidation rate of $\mathrm{p}$ sylene decreases in the later stage of the reaction when the reaction temperature is too high or the water concentration is too low. This retardation of reaction due to the low concentration of water may be partly overcome with the addition of potassium. The oxidation of o-xylene is faster than that of $\mathrm{p}$-xylene and $\mathrm{nt}-\mathrm{xylene}$ in the earlier stage of the reaction. However, the rate of oxidation in the later stage of the reaction is in the order of $\mathrm{p}$-xylene $>\mathrm{m}$ - $\mathrm{xylene}>\mathrm{O}$ xylene due to the retardation of o-xylene oxidation.

\section{References}

1. http: www hvosungchemical.comenglish:

2. Ittp : www utm edudepartments artscichemistry: TerephthalicAcid.html

3. Chavan. S. A.: Halligudi. S. B.: Srinivas. D.: Rantnasamy. P. J. Hol. Catal A 2000 . 161.49

4. Partenheimer. W. Catal. Today 1995, 23.69

5. Sheldon, R. A.: Kochi. I. K. Metal-Catalyzed Oxidations of Organtic Contpounds: Academic Press: New York. 1981: Ch. 5 and $\mathrm{Ch} .10$.

6. Cincotti. A.: Orru. R.: Cao. G. Catal. Todav 1999.52.331.

7. Cincotti. A.; Oru R.: Broi. A.: Cao. G. Chem. Eng. Sci. 1997. 52. 4205 .

8. Igarashi. J.: Lusztrk, J.: Ingold. K. U. J. Am. Chem. Soc 1992. 114. 7719 .

9. Igarashi. J.: Jensen. R. K.: Lusztyk. J.: Korcek. S.: Ingold. K. U. J.
An. Chem. Soc. 1992, 114, 7727

10. Roffia. P.: Calina. P.: Tonti. S. Oxidation Comm. 1985/1986. 8 . 167.

11. Dugmore. G. M.: Powels. G. J.: Zeelie. B. J. Mol Catal A 1995. 99. 1.

12. Partenheimer. W. In Catalvsis of Organic Reactions: Kosak, J. R.; Johnson T. A. Eds.: Marcel Dekiker: New York. 1994: p. 188.

13. Partenheimer. W: Kaduk. I. A. Stud Sinf. Sci. Catal. 1991. 66. 613.

14. Partenheimer. W. In Catalysis of Organic Reactions: Blackbum D W. Ed.: Marcel Dekker: New York, 1990: p. 321.

15. Akhtar, S.; Zaidi, H. Appl. Catal. 1986. 27.99.

16. Hanotier. J Hanotier-Bridoux. M. J. M fol. Catal 1981, 12. 133.

17. Okada. T.: Kamiya. Y. Bull. Chem. Soc. Jpn. 1979.52.3321.

18. Harustiak. M.: Honnec. M.: Ilavshy. T. J. Mol. Catal. 1989. 53. 2019.

19. Hronec. M:- Ilavshy J. React. Kinet. Catal. Lett. 1987, 33, 323

20. Jacob. B. R.: Varkey. S. P.: Ratnasamy. P. Appl Catal A 1999. 182.91.

21. US Pat. 5760288 (1998). to Mitsubishi Chemical Corp.

22. Yoo. J. S.: Лhung. S. H.: Lee. K. H.: Park. Y-. S. Appl. Catal .A 2002. 223. 239.

23. Gipe. R. K; Partenheimer. W. Stud. Surf. Sci. Catal. 1997, 110. 117.

24. Chester. A. W.: Scott. E. J. Y.: Landis. P. S. J. Catal. 1977, 46. 308.

25. Chem Systems. Terephnhalic acid. 9798-5. Feb. 1999.

26. Thung. S. H.: Lee. K. H.: Park. Y.-S. Appl. Catal A 2002 in press. "Effects of alkali metals on the liquid phase oxidation of $p$ xylene"

27. Reference no. 4. P. 23.

28. Jhung. S. H. unpublished results.

29. Lee. K. H.: .hung. S. H. unpublished results. 